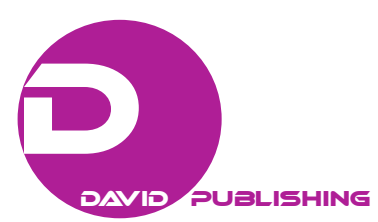

\title{
Sustainable Management of Water Resources: Cultural Roots of a Stakeholder Perspective
}

\author{
Massimo Mariani, Paola Amoruso \\ Lum Jean Monnet University, Casamassima, Italy
}

\begin{abstract}
Sustainable use of water resources is based on the analysis of the above-mentioned sector, characterized by persistent delays and imbalances, referring to the Italian context, which reflects a problem of global dimension. As a consequence of the current scenario, the current paper discusses possible success resulting from the application of a stakeholder perspective in order to achieve a sustainable management of these strategic resources. Specifically, it points out the importance to build the study on the analysis of national territory carried out through cultural dimensions, in order to evaluate the eventual parallelism between national peculiarities and requirements of a stakeholder perspective. Namely, the performed analysis will be referred to Hofstede's classification, which identifies six cultural dimensions, considered driven factors of different national cultures. A comparison between Italian scores on these factors and the requirements of a stakeholder-based structure, will allow verifying the possible correlation between a stakeholder's management and the Italian context, from a cultural point of view, in order to evaluate the chance of success of a stakeholder strategy in the reference background.
\end{abstract}

Keywords: sustainability, stakeholder management, organizational culture, water resources, cultural dimensions, Hofstede's classification

\section{Introduction}

The current work deals with sustainable use of water resources, from an economic point of view as well as social and environmental. Water resources are among the most strategic for the maintenance of qualitative and quantitative standards of social and economic conditions of a society, and often represent a limiting factor for development. Particularly, the present work deals with the management of this valuable resource, and the possible efficiency which could be achieved by taking into account cultural background of the reference context. Namely, the performed qualitative analysis will be related to the Italian framework; the developed study will be referred to Hofstede's classification, which identifies six cultural dimensions, presented as driven factors of different national cultures. A comparison between Italian scores on these dimensions as well as the requirements of a stakeholder-based structure, will allow determining a possible match of the stakeholder management with the Italian context, from a cultural point of view, in order to evaluate the chance of success of a stakeholder's management of water resources within the domestic scenario. In first instance, it has described

\footnotetext{
Massimo Mariani, associate professor of corporate finance, Department of Economics, Lum Jean Monnet University, Casamassima (Ba), Italy.

Paola Amoruso, Ph.D. student, Department of Economics, Lum Jean Monnet University, Casamassima (Ba), Italy.

Correspondence concerning this article should be addressed to Massimo Mariani, Department of Economics, Lum Jean Monnet University, Casamassima (Ba), Italy.
} 
the current Italian situation of the use of water resources; secondly, an overview of fundamental issues of sustainability is provided and the importance in existing literature of how the concept of nationality influences the success of adopted strategy in economic fields is highlighted. Therefore, on the basis of the above assessment, a qualitative analysis is performed, by comparing Italian scores on Hofstede's cultural dimensions and the requirements of a stakeholder-based structure, given a possible prediction of benefits obtained through the adoption of a stakeholder strategy in water management.

\section{Background and Theoretical Basics}

Water resources are essential for a large number of human activities and different application fields are each other related (Grigg, 1996). ISTAT survey on the water cycle and Italian Supervisory Committee analysis on the use of water resources (CO.VI.RI.) ${ }^{1}$ provides data which describe a sector characterized by persistent delays and imbalances, mainly due to high fragmentation of management authorities, to incorrect operating modes of services and to widespread structural and qualitative deficits (Arena, Cannarozzo, \& Mazzola, 2006).

In 2008 in Italy, $92.5 \mathrm{~m}^{3}$ of drinking water per capita was granted, with an increase of $1.2 \%$ over the past decade. This value is representative of water consumed, measured referring to individual users, and the estimated water not measured, but consumed for different uses (public places, fountains, water washing of roads, watering of public parks, etc.). The distribution of drinking water is very heterogeneous on the Italian territory. With $107.1 \mathrm{~m}^{3}$ per inhabitant, the northwest of Italy is the geographical distribution which shows a greater supply of drinking water per capita by the municipal network of distribution, about $15 \mathrm{~m}^{3}$ more than the national average. The highest regional values are those of the Autonomous Province of Trento $\left(127.4 \mathrm{~m}^{3}\right.$ per inhabitant) and Valle d'Aosta $\left(121.9 \mathrm{~m}^{3}\right)$. Central Italy presents a value of $96.0 \mathrm{~m}^{3}$ per capita, slightly higher than the national average. Southern Italy is the region with the lowest supply of drinking water: the annual volume of water supplied per capita is of $80.6 \mathrm{~m}^{3}$ and presents, in this case, a strong regional variability, with a maximum value of $99.2 \mathrm{~m}^{3}$ in Calabria and a minimum one in Puglia of $63.5 \mathrm{~m}^{3}$ (the latter is the region with the lowest value of water delivered per inhabitant). The Italian situation actually reflects a problem of global dimension. In fact, considering per capita consumptions in the $27 \mathrm{EU}$ countries, Italy, with a value of $92 \mathrm{~m}^{3}$ per capita per year, is above the European average of $85 \mathrm{~m}^{3}$ per capita per year. Particularly, comparing the phenomenon in some large EU countries, the average consumption in Italy is lower than Spain $\left(100 \mathrm{~m}^{3}\right)$ and UK $\left(110 \mathrm{~m}^{3}\right)$; nevertheless, it is higher than Netherlands $\left(73 \mathrm{~m}^{3}\right)$ and Germany $\left(57 \mathrm{~m}^{3}\right)$. The water's footprint in Italy, which is the amount of freshwater used to produce goods and services, is of 132 billion cubic meters per year, 6.309 litres per capita per day. Italy is the third importer of virtual water in the world (62 billion cubic meters per year), after Japan and Mexico and before Germany and United Kingdom. Regarding investments, Italy spends $30 \%$ of the amount invested by UK; in fact, Italy invests every year $€ 30$ per inhabitant, Germany $€ 80$, France $€ 90$, and UK €100. It is estimated that, to bring the level of the Italian water infrastructure in line with European standards, it would be required to invest 65 billion euro in three decades. In 2008, there was, at national level, a loss of $47 \%$ of drinking water, with the largest losses in Puglia, Sardinia, Molise, and Abruzzo, where for every 100 litres of water delivered, about 80 litres more enter the network; the lower losses are observed in Lombardy, Trento, and Bolzano.

\footnotetext{
1 The following data are provided by ISTAT and referred to different surveys of 2008 and 2012.
} 
In 2012, the total volume of water withdrawn for drinking was of 9.5 billion cubic meters, with an increase of 3.8\% compared to the data of 2008. The volume entered municipal drinking water distribution network is of 8.4 billion cubic meters, 385 litres per day per inhabitant. The value is $2.6 \%$ more than 2008's volumes, 5.2 billion cubic meters is the volume delivered to users, which corresponds to a daily consumption of water of 241 litres per capita, 12 litres per day less compared to the data of 2008. Overall, the dispersion of municipal drinking water distribution networks is of 3.1 billion cubic meters. Therefore, $37.4 \%$ of volume in the network does not reach end users. There has been a relative worsening of situation compared to 2008, when dispersions were of $32.1 \%$. Considering the data of 2008, losses of the regional network show the most critical situations in the Islands and in the Centre-South, with the exception of Abruzzo and Puglia, which recently has healed some situations of strong dispersion. Although with lower levels, even the northern regions present a general worsening of recorded losses.

With the attention to the current global scenario, the European Commission submitted to Parliament on November 14, 2012 the report "Blueprint to safeguard Europe's water resources", the first of a series of five reports, which shows the current state of water with the final aim of implementing it by 2015, as required by The European Framework Directive (WFD); among approaches expected from the report, there is the introduction of new strategies for resource management.

Generally, the whole global scenario is affected by several emerging problems and risks, related to water resources management. Pollution trends and impacts of hazardous pollutants remain uncertain; water resources and water demands remain unbalanced at various levels; groundwater abstraction and over-exploitation have serious environmental impacts. Moreover, climate change is impacting on both water availability and demands the occurrence of extreme events (Mazzola, 2006). These problems encompass important socioeconomic issues, such as legal and regulatory frameworks for water resources management, methods to balance conflicting human and ecosystem demand, financial sustainability of water management system (Barraquè, 2007a; 2007b). This shows the complexity water managers face for sustainable management. Hence, sustainable development is one of the main guiding principles for modern societies; sustainability has become, in general, a cogent paradigm for the management of natural resources. The Brundtland Report ${ }^{3}$ defined sustainable development as "development that meets the interests of the present without compromising the ability of future generations to meet their own interests”. The relationship between environment and economic growth is strongly related to scarce resources, pollution, and significant population increase. The crux of the issue is linked to the ability of the market to allocate resources efficiently. Therefore, a particular perspective was provided by Environmental Kuznets Curve (EKC), a vehicle for describing the relationship between measured levels of environmental quality and related measures of income per capita, across time, as shown in Figure 1 (Primer, 2002). Specifically, there is evidence that the level of environmental degradation and conventionally measured income per capita follow an inverted-U-shaped relationship. The EKC's statistical relationship suggests that, as development and industrialization progress, environmental damage increases due to greater use of natural resources, increasing emission of pollutants, the operation of less efficient and relatively dirty technologies, the high priority given to increase material output, and disregard for the environmental consequences of growth. However, as economic growth continues and life expectancies increase, cleaner water, improved air quality, and a generally cleaner habitat become more valuable as people

\footnotetext{
${ }^{2}$ Environment Directorate-General of the European Commission.

3 The report "our common future" is issued by the UN World Commission for the Environment and Development, 1987.
} 
begin to invest their incomes in environmental quality. Much later, in the post-industrial stage, cleaner technologies and a shift to information and service-based activities combine with a growing ability and willingness to enhance environmental quality. In this view, the positive correlation between economic development and pollution is offset by the trend of investing part of the growing prosperity in the protection of the environmental quality.

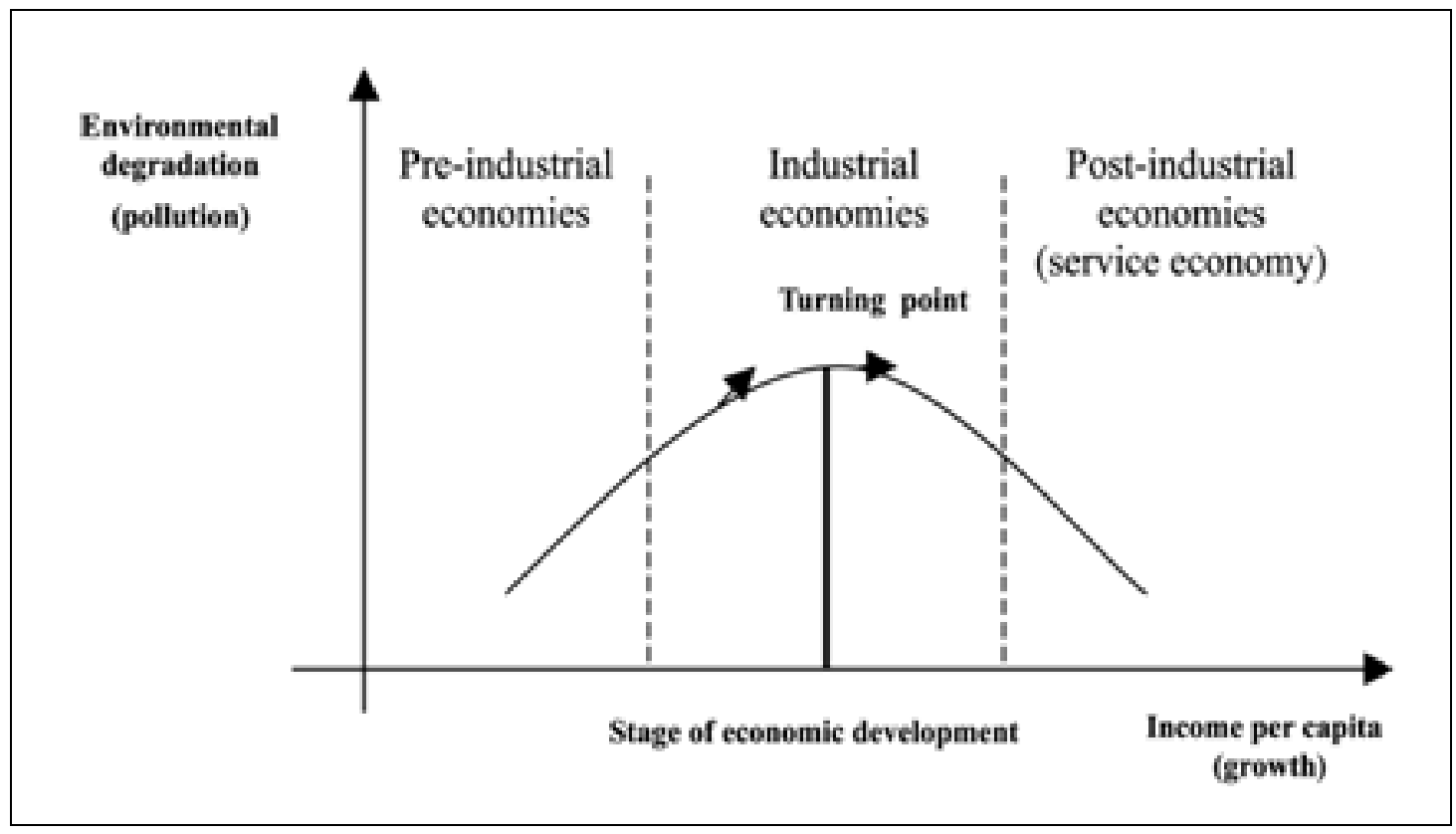

Figure 1. Environmental kuznets curve. Source: Panayotou (2003).

Water and sustainability are closely linked, since the provision of water in sufficient quantities and of high quality has important impacts on environment, society, and industry as well as the wellbeing of future generations. Water is recognized as the most crucial resource, in part because it underpins basic ecosystem functions; at the same time, it is distributed variably over the planet, and because of scarcity as well as lack of financial resources, it fails to meet essential human needs. It requires a challenge in water management in order to mitigate the inequitable and inefficient distribution of water resources, reducing their vulnerability to excessive demands and limiting the impact of both land and water-based activities on their quality. These needs stand for a widespread demand of a "rational management". Thanks to the unprecedented attention, sustainability has received over the last several years, chief executives have strongly set sustainability priorities and goals and companies have undertaken numerous initiatives focused on enhancing environmental performance. Environmental sustainability objectives include controlling anthropogenic impacts on the global climate, reducing pollution, preserving natural resources, and enhancing ecosystems and habitats (Rosin, Electris, \& Raskin, 2010). Key action dimensions contributing to these ends are divided into three sectors: mitigate greenhouse gas emissions (reducing combustion of fossil-fuels and sequester $\mathrm{CO}^{2}$ emissions; minimizing then reverse emissions from land-use changes; and reducing other greenhouse gas emissions); protecting natural resources (reducing air and water pollution; eliminating emissions of toxic chemicals; reducing mineral flows through economy and recycle intensively; and reducing water stress); and preserving habitats (reducing urban 
sprawl; protecting forests and other ecosystems; fish sustainably; and promoting ecological agriculture $)^{4}$. Meeting all these objectives requires improvements in technology and significant changes in lifestyles, and ultimately, in core values (Donaldson, 1989). To radically reduce human impacts on the environment, technological progress is necessary, but it is not sufficient. Indeed, a re-thinking in the management of natural resources is also required in order to reach these aims.

Following a triple-bottom approach (Elkington, 1997), rational management must be able to ensure:

- multiple use (drinking, irrigation, hydropower, and industrial), such as uses not directly productive, but essential for environmental safety (i.e. the river minimal basic flow downstream of the reservoirs, the preservation of wetlands and everything else needed to conserve natural ecosystems). Often, the different uses conflict with each other because they answer different logics, ratio (i.e. different fares, user laws, quality, and quantity);

- ecological sustainability of resource, which is limited and degradable that means that the available stock of resource must be used according to a purpose priority scale (i.e. drinking, irrigation, ...) in order to satisfy the current needs, but also to preserve the resource for future generation;

- economical sustainability, for what it is a necessary optimization of management and processes, in order to guarantee low fares, compatible with cost-benefit analysis;

- ethical-social sustainability, that means an equitable sharing and accessibility for all users.

As a consequence of the emerging scenario, in order to reach the above aims, it is necessary to consider different territory conditions, at national and regional level. In this view, it is not possible to ignore the peculiarities of each country, which strongly influence the possible success of adopted practices (Schein, 1990). The above-mentioned peculiarities rest on the concept of nationality, which is related to prevalent way of thinking and mode of operation (Sun, 2008). They deeply affect a wide range of areas of action, including all the possible adopted strategies in a particular context (Barron \& Schneckenberg, 2012). For this reason, also the management of resources, as it involves the adoption of practices and strategies, will be influenced by national belonging (Chatman \& Eunyoung Cha, 2003). As asserted by Hofstede (1984), the nature of management skills is culturally specific and, for this reason, a management technique suitable in a certain national culture is not necessarily adequate in another. Consequently, the culture of the national context in which an organization operates influences the management strategy through the "collective mental programming" of its members and its managers (Hofstede, 1994). The relevance of Hofstede's work has been more recently evidenced by Drogendijka and Slangenb (2006) in 2006. Therefore, nationality is important to management for at least three reasons: the first is political. Nations are political units, rooted in history, with their own institutions: forms of government, legal systems, educational systems, labor, and employer's association systems. The second reason why nationality is important is sociological. Nationality, or regional belonging, has a symbolic value to citizens, since they all derive part of their identity from it. The third reason is psychological, as thinking is partly conditioned by national culture factors. This is an effect of early life experiences in the family and later educational experiences in schools and organizations, which is not the same across national borders (Hofstede, 1983). The six cultural dimensions, presented by Hofstede (1983) to identify some driven factors of the culture of a particular country, which are:

1. Power distance, related to the different solutions to the basic problem of human inequality.

\footnotetext{
${ }^{4}$ Buildings and Climate Change Summary for Decision-Makers, United Nations Environment Programme (2009).
} 
2. Uncertainty avoidance, related to the level of stress in a society in the face of an unknown future.

3. Individualism versus collectivism, related to the integration of individuals into primary groups.

4. Masculinity versus femininity, related to the division of emotional roles between women and men.

5. Long term versus short term orientation, related to the choice of focus for people's efforts: the future or the present and past.

6. Indulgence versus restraint, related to the gratification versus control of basic human desires related to enjoying life.

As a matter of fact, the intrinsic aspects of a nation widely affect the success of the adopted practices. As a consequence, corporate sustainability could be improved by a cultural change, and for this reason, organizations should develop sustainability-oriented organizational culture (Linnenluecke \& Griffiths, 2010). According to this idea, competitive value framework (CVF) of organizational culture is used to illustrate the relationship between corporate sustainability and organizational culture. It identifies four different dimensions (internal-external dimensions and control-flexibility dimensions); different combinations of these four dimensions generate various culture types with peculiar characteristics. Each quadrant emphasizes different aspects of the organization (people, stability, and task accomplishment) and they can and do coexist within an organization, although some values could be more dominant than others. There is a strong parallelism between the quadrant of the CVF and the major theoretical issues in managerial ideologies such as "the engagement with the natural environment can enhance firm performance, economic sustainability is not enough"; "Human relationships and creation of human work environment, placing emphasis on internal staff development”; "Rational planning and organizing in light of environmental demands"; and "Importance of external environment in affecting the behavior, structure, and life change of organizations". The leading result of this analysis is a change in managerial approach; in order to move towards corporate sustainability, it appears that leaders have to abandon a purely economically driven paradigm and achieve a more balanced set of socially and environmentally responsible values. An engagement with corporate sustainability practices, particularly the publication of a corporate sustainability policy as well as the integration of environmental performance indicators in employee evaluation, should be an important aspect (World Economic Forum, 2013).

In the case of water resources, existing literature has stressed the need of an integrated water resources management, in which cultural adaptation has become a major issue of concern (Pahl-Wostl, Tàbara, Bouwen, Craps, Dewulf, Mostert, ... Taillieu, 2008). Thus, the relation among national culture, the historical, and political differences in the respective countries, and their practical experience with public participation in policies and practices in water management are considered important to support the implementation of the EU Water Framework Directive (Enserink, 2007). Rivera-Vazquez, Ortiz-Fournier, and Rogelio Flores (2009) identified, through an analysis based on Hofstede's dimensions, cultural barriers delay knowledge production and sharing in organizations of the Municipality of Caguas at the Commonwealth of the Puerto Rico including in their sample an international water system company. However, in the light of the needs of society, the present work has the aim to make a contribution to such enforcement, proving effective success in Italy associated with a change in managerial approach of water resources, moving on to a stakeholder perspective. The performed analysis has the aim to demonstrate how managerial end economic decisions are affected by cultural factors, which cannot be ignored, since influencing the effectiveness (Vitell, Nwachukwu, \& Barnes, 1993). This general idea, in the present case, is applied to a particular field, that of water resources, nevertheless, it is traceable to all sectors of society's economy. 


\section{Research Design}

\section{Research Framework}

Based on previous activities, it will be necessary to understand the territorial peculiarities and, subsequently, to compare them with main requirements of stakeholder perspective. Hofstede (1983) presented in his work of 1983, a research project across 50 countries, including Italy. However, a deeper analysis can discover further differences among several Italian macro-areas (North, Centre, and South). The results presented by an accurate analysis, developed according to Hofstede's classification, adduce a clear cultural framework of Italy, assigning a score for every above-mentioned dimension ${ }^{5}$. It provides insights in Hofstede's research into national and organizational culture. Specifically, the country scores presented on the dimensions are relative; they are related to other data regarding the countries concerned. Power distance, for example, is correlated with income inequality, and individualism is correlated with national wealth. In addition, masculinity is related negatively with the percentage of national income spent on social security. Furthermore, uncertainty avoidance is associated with the legal obligation in developed countries for citizens to carry identity cards, and pragmatism is connected to school mathematics results in international comparisons (Hofstede, 2011).

\section{Italy's Score}

For the Italian case, according to the data presented by the Hofstede Centre, cultural scores are the following (Figure 2):

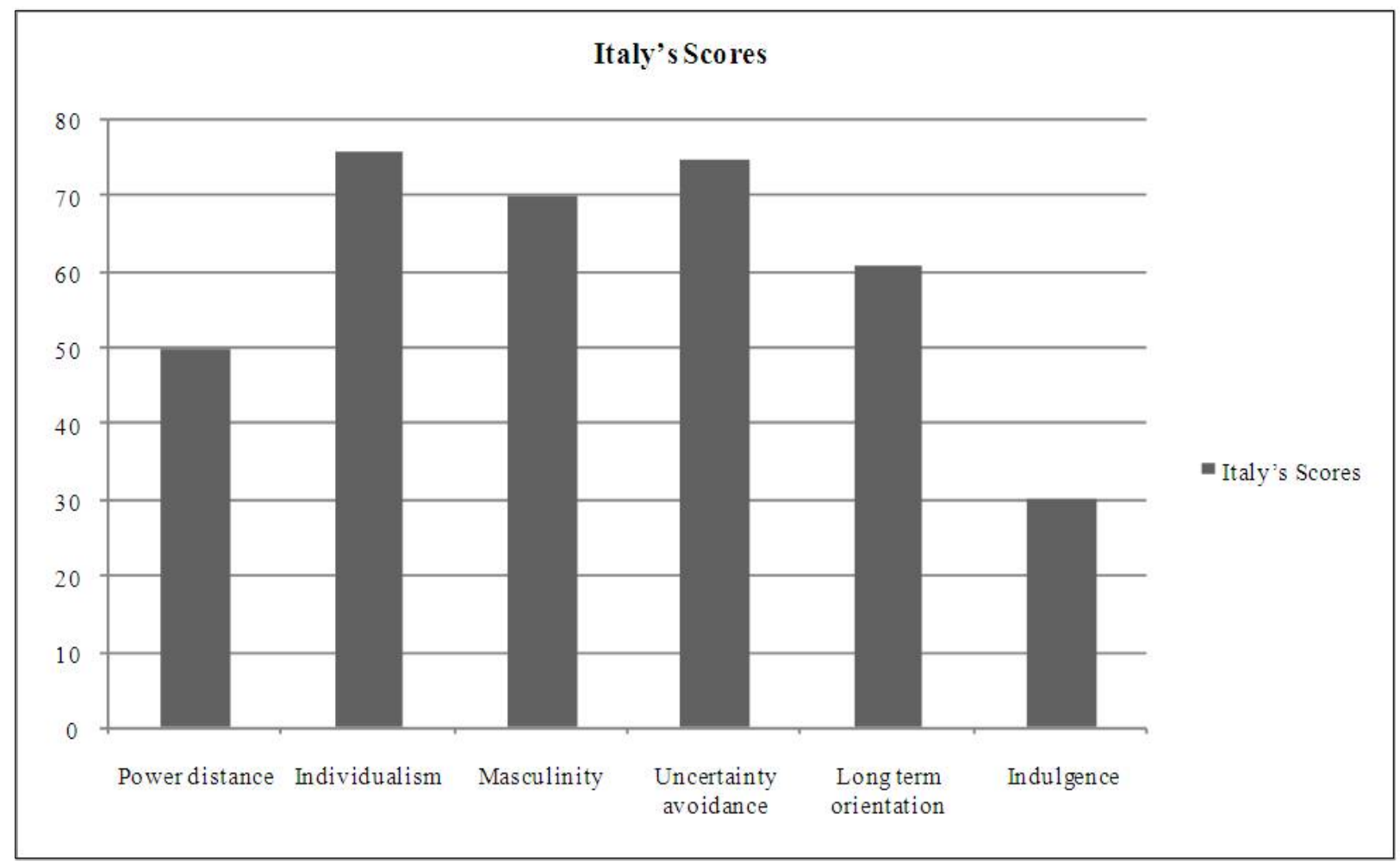

Figure 2. Italy's score on Hofstede’s model. Source: presented data are provided by The Hofstede Centre.

\footnotetext{
${ }^{5}$ The analysis is provided by "the Hofstede Centre”-http://geert-hofstede.com/.
} 
Power distance. With a score of 50, Northern Italy tends to prefer equality and a decentralization of power and decision-making. The younger generation generally dislikes control and formal supervision and prefers teamwork and an open management approach. Certainly, the high score on individualism accentuates the aversion of being controlled and tells what to do. In Southern Italy, all the consequences of the above-mentioned index are often high, quite the opposite of Northern Italy.

Individualism. At a score of 76, Italy is an individualistic culture, "me" centered, characterized by subjects strongly focused on themselves. In this view, having own personal ideas and objectives in life is a fundamental point and the route to happiness is through personal fulfillment. This dimension presents differences in Southern Italy where less individualistic behavior can be observed: the family network and the group one belongs have relevant influence on society.

Masculinity. At 70, Italy is a masculine society—highly success oriented and driven. Children are taught since the beginning that competition is good and the material demonstration of personal success is a fairly normal occurrence. As the working environment is the place where every Italian can reach his/her success, competition among colleagues for making a career can be very strong.

Uncertainty avoidance. At 75 , Italy has a high score on uncertainty avoidance which means that, as a nation, Italians are not comfortable in ambiguous situations. Formality in Italian society is fundamental and, for this reason, the Italian penal and civil code are complicated with clauses, codicils, etc. In work terms, high uncertainty avoidance results in large amount of detailed planning. As a consequence, the low uncertainty avoidance approach (whit flexible planning to changing environment) in this context can be very stressful.

Long term vs. short term orientation. Italy's high score of 61 on this dimension shows that Italian culture is typically pragmatic. In societies with a pragmatic orientation, people believe that truth is influenced by situation, context, and time. They show an ability to adapt traditions easily to changed conditions, a strong propensity to save and invest thriftiness and perseverance in achieving results.

Indulgence vs. restraint. A low score of 30 indicates that Italian culture is restraint-oriented. Societies as the Italian one, with a low score in this dimension, have a tendency to cynicism and pessimism. Moreover, in contrast to indulgent societies, they do not put much emphasis on leisure time and strictly control the gratification of their desires. People with this orientation have the idea that their actions are restrained by social norms and feel that indulging themselves is somewhat wrong.

\section{Discussion}

A stakeholder-based structure is characterized by aggregations management aimed to vertical and horizontal integration. Independent exercise of the functions and appropriate interaction between the parties involved can fill the imbalances related to quality of service, in terms of management, waste and economic, and environmental and social key performance indicators (Freeman, Harrison, \& Wicks, 2007). This change of perspective can create conditions of convenience for the exercise of business activities to ensure innovation and development. Moreover, it can allow overcoming the extreme heterogeneity, that characterizes the Italian context, starting from the involvement of different subjects and paying attention to the huge diversification of conditions. This approach would lead to legitimization strategies including transparency, democratic access, and an improvement of the regulatory asset, also ensuring respect to the cultural framework and the creation of expertise.

This perspective can be compatible with a score in power distance which indicates a preference of equality, even though differences of behavior in the South are found. However, the following two dimensions are 
characterized, in the Italian case, by negative index, from a stakeholder perspective. Therefore, a strong individualistic approach is not useful because of too much focus on personal goals and success. Societies that are characterized as masculine, such as Italy, encourage individuals to be ambitious, competitive, and to strive for material success. These factors may contribute significantly to one's engagement in unethical behavior. Thus, decision-makers in some cultures (i.e., masculine) may not even perceive certain ethical problems because they are not defined by their culture as involving ethics. Based on Hofstede's conceptualization of the dimension of uncertainty avoidance, it is suggested that business practitioners from societies that are strong on uncertainty avoidance are more likely to be intolerant of any deviations from group/organizational norms. This reasoning concurs with Ouchi's (1981) theory regarding organizational cultures in Japanese and American firms. Japan, as Italy, is characterized by a high degree of uncertainty avoidance; Ouchi (1981) stated that type $\mathrm{Z}$ organizations (i.e., Japanese firms) have a high degree of consistency in their internal cultures. These firms involve intimate associations of people who are tied together through a variety of bonds, in contrast with a hierarchical organization (i.e., American firms) where there is a great deal of mistrust; the individual in the type $\mathrm{Z}$ organization naturally seeks to do that which is in the common good (Argandona, 1998). This interpretation of this fourth dimension could be in accordance to stakeholder theory. Finally, the pragmatic aspect of Italian culture can be considered as positive in this view, because it is indicative of long-term orientation trend which is of course at the basis of a stakeholder approach, and in general of a successful change in favor of sustainable management (Freeman, 1984). The last dimension is not very influential in this context because it focuses on aspects not covered by the other five dimensions, but known from literature as "happiness research". This analysis points out contrasting aspects in the parallelism between Italian culture and stakeholder theory. Some of them suggest compatibility, although, others prove an obvious discord. As a consequence, this analysis does not provide a final and univocal response to the leading question about the possible success of a stakeholder perspective in the considered cultural context; however, it adds a piece to the puzzle, trying to create a concrete and empirical basis to validate the effectiveness of a re-thinking in the management. The position of Italy on these dimensions allows making some predictions on the possible results, derived from the pursuit of the required change. The truthfulness of this kind of analysis is verified in light of the basic concept that people of different countries may think, feel, and act in various ways when confronted with basic problems of society. Effective and realistic management practices are strictly related to the cultural context of action (Hofstede, 1993). This perspective explains the failure or, otherwise, contradictory results that, for example, a particular and single multinational can obtain in different countries. In this perspective, the meaning of management differs to a larger or smaller extent from one country to the other, and it takes considerable historical and cultural insight into local conditions to deeply understand its processes and problems.

\section{Conclusions}

This analysis, based on Hofstede's classification, should be useful in order to validate the effectiveness of a stakeholder approach; in this regard, the present work aims to add a deep theoretical basis to this topic, taking into account essential cultural aspects related to the specific reference context. The desirable change in water resources management is necessary because, in current and future conditions of water scarcity, many nations cannot meet demand through increased water supply only; water demand management is therefore imperative. However, it is necessary to take into account that a unique solution does not exist but still it's possible to find the best one depending on the case of analysis. 
In this perspective, it is essential to consider some aspects, closely linked to nationality, regarded as cultural belonging, since they are representative of the reference context; as a consequence, the characteristic that seems indispensable is the flexibility, which allows properly considering these elements. This study shows, for certain aspects, a possible improvement which can be obtained from the application of a stakeholder approach, which would fit well with some peculiarities of the Italian cultural background. Considering the scores obtained in these dimensions, stakeholder practices could prove successful. Nevertheless, the analysis indicates an incompatibility between some of the requirements at the basis of this perspective and the corresponding fundamental behavioral attitudes of this country. Management is a phenomenon that cannot be isolated from other processes taking place in a society. Nevertheless, there is an intrinsic limit in the modeling of these cultural dimensions; they are associated to scores, based on average behavior of individuals. For this reason, they do not take into account one peculiar element which distinguishes culture: the heterogeneity. This aspect is a limiting factor since it means that the analysis provides just a general description of the cultural background, maybe approximating the results. However, despite this element, it is possible to conclude that social attitudes are essential in order to move toward an effective change, aimed to reach a sustainable approach and this requirement is certainly necessary, considering the growing attention the global context is paying toward environment.

The possible future directions of this work could validate the change of perspective in the management of water resources, laying additional ground from an economic point of view. Then, it would be useful to point out benefits, in terms of saving as well as of growing investments, which would be obtained with the introduction of private investors, with a particular focus on the mutual collaboration among involved parties. This perspective would allow proving that a sustainability-oriented management, aimed to respect resources, is not synonymous with costs but it is equivalent to benefits. In this view, recorded data on current scenario merit further consideration as they show a growth in global economy as well as a contemporary decrease in pollution phenomena.

\section{References}

Arena, C., Cannarozzo, M., \& Mazzola, M. R. (2006). Multi-year drought frequency analysis at multiple sites by operation hydrology-A comparison of methods. Physics and Chemistry of the Earth, 31, 1146-1163.

Argandona, A. (1998). The stakeholder theory and the common good. Journal of Business Ethics, 17(9), 1093-1102.

Barraquè, B. (2007a). Aspects institutionnels, socio-économiques, juridiques et techniques de la gestion de l'eau en Europe. In J. P. Ammigues, D. Le Quéau, P. Mazzepa, and J. C. Menault (Eds.), Sociétés-environnement. Regards croisés. Paris: L'Harmattan.

Barraquè, B. (2007b). Panorama internazionale ed Europeo dell’Industria dell'acqua. In R. Fazioli (Ed.), Economia e Politica Della Regolazione del Servizio Idrico. Modelli ed Esperienze a Confronto (pp. 53-76). Bologna: Clueb.

Barron, A., \& Schneckenberg, D. (2012). A theoretical framework for exploring the influence of national culture on Web 2.0 adoption in corporate contexts. Electronic Journal Information Systems Evaluation, 15(2), 176-186.

Rivera-Vazquez, J. C., Ortiz-Fournier, L. V., \& Rogelio Flores, F. (2009). Overcoming cultural barriers for innovation and knowledge sharing. Journal of Knowledge Management, 13(5), 257-270.

Chatman, J. A., \& Eunyoung Cha, S. (2003). Leading by leverage culture. California Review Management, 45(4), $20-34$.

Donaldson, T. (1989). The ethics of international business. New York: Oxford University Press.

Drogendijka, R., \& Slangenb, A. (2006). Hofstede, Schwartz, or managerial perceptions? The effects of different cultural distance measures on establishment mode choices by multinational enterprises. International Business Review, 15, 361-380.

Elkington, J. (1997). Cannibals with forks: The triple bottom line of 21st century business. Oxford Capstone Publishing Ltd

Enserink, B., Patel, M., Kranz, N., \& Maestu, J. (2007). Cultural factors as co-determinants of participation in river basin management. Ecology and Society, 12(2), 24. 
Freeman, R. E., Harrison, J. S., \& Wicks, A. C. (2007). Managing for stakeholders: Survival, reputation, and success. New Haven \& London: Yale University Press.

Freeman, R. E. (1984). Strategic management: A stakeholder approach. Boston: Pitman Press.

Grigg, N. S. (1996). Water resources management. Principles, regulations and cases. McGraw Hill Professional.

Hofstede, G. (1983). The cultural relativity of organizational practices and theories. Journal of International Business Studies, 14(2), 80-95.

Hofstede, G. (1984). Cultural dimensions in management and planning. Asia Pacific Journal of Management, 1(2), 81-99.

Hofstede, G. (1993). Cultural constraints in management theories. Academy of Management Perspectives, 7(1), 81-94.

Hofstede, G. (1994). Management scientists are human. Management Science, 40(1), 4-13.

Hofstede, G. (2011). Dimensionalizing cultures: The Hofstede model in context. Online Readings in Psychology and Culture, 2(1), 3-26.

Linnenluecke, M. K., \& Griffiths, A. (2010). Corporate sustainability and organizational culture. Journal of World Business, 45, 357-366.

Mazzola, M. R. (2006). L’approvvigionamento idrico primario. In C. De Vincenti and A. Vigneri (Eds.), Le virtù della Concorrenza (pp. 323-334). Bologna: Il Mulino.

Ouchi, W. G. (1981). Theory Z: How American business can meet the Japanese challenge. Boston: Addison-Wesley.

Pahl-Wostl, C., Tàbara, D., Bouwen, R., Craps, M., Dewulf, A., Mostert, E., ... Taillieu, T. (2008). The importance of social learning and culture for sustainable water management. Ecological Economics, 64, 484-495.

Panayotou, T. (2003). Economic growth and the environment. Economic Survey of Europe No.2 (Chapter 2).

Primer, A. (2002). The environmental kuznets curve. Property an Environment Research Centre.

Rosin, R. A., Electris, C., \& Raskin, P. D. (2010). Global scenarios for the century ahead: Searching for sustainability. Sustainability, 2(8), 2627-2651.

Schein, E. H. (1990). Organizational culture. American Psychologist, 45(2), 109-119.

Sun, S. (2008). Organizational culture and its themes. International Journal of Business and Management, 3(12), $137-141$.

United Nations Environment Programme. (2009). Buildings and Climate Change Summary for Decision-Makers.

Vitell, S. J., Nwachukwu, S. L., \& Barnes, J. H. (1993). The effects of culture on ethical decision-making: An application of Hofstede's typology. Journal of Business Ethics, 12(10), 753-760.

World Economic Forum. (2013). Sustainable Consumption: Stakeholder Perspective. 